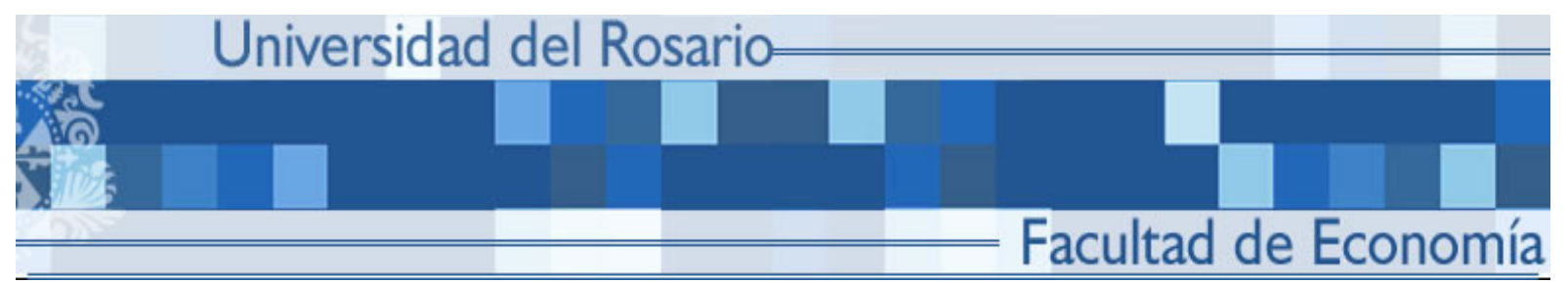

\title{
ON THE DESIGN OF EDUCATION CONDITIONAL CASH TRANSFER PROGRAMS AND NON EDUCATION OUTCOMES: THE CASE OF TEENAGE PREGNANCY.
}

Darwin Cortés

Juan Gallego

Darío Maldonado

No. 100

Julio 2011 


\title{
On the design of education Conditional Cash Transfer programs and non education outcomes: The case of teenage pregnancy.*
}

\author{
Darwin Cortés ${ }^{\dagger} \quad$ Juan Gallego $\quad$ Darío Maldonado ${ }^{\ddagger}$
}

July 18, 2011

\begin{abstract}
We investigate the effect of education Conditional Cash Transfer programs (CCTs) on teenage pregnancy. Our main concern is with how the size and sign of the effect may depend on the design of the program. Using a simple model we show that an education CCT that conditions renewal on school performance reduces teenage pregnancy; the program can increase teenage pregnancy if it does not condition on school performance. Then, using an original data base, we estimate the causal impact on teenage pregnancy of two education CCTs implemented in Bogotá (Subsidio Educativo, $S E$, and Familias en Acción, FA); both programs differ particularly on whether school success is a condition for renewal or not. We show that $S E$ has negative average effect on teenage pregnancy while $F A$ has a null average effect. We also find that $S E$ has either null or no effect for adolescents in all age and grade groups while $F A$ has positive, null or negative effects for adolescents in different age and grade groups. Since $S E$ conditions renewal on school success and $F A$ does not, we can argue that the empirical results are consistent with the predictions of our model and that conditioning renewal of the subsidy on school success crucially determines the effect of the subsidy on teenage pregnancy.
\end{abstract}

JEL codes: D12, I28, I38, J13.

Keywords: Teenage risk taking behavior, Teenage pregnancy, Education, Conditional Cash Transfers, Incentives.

\footnotetext{
*This paper is part of the results of the project "Evaluating policies to reduce teenage childbearing in Bogotá, Colombia: the effect of policies reducing costs of education faced by households" funded by PEP-BIDGRADE Teenage Childbearing Initiative in Latin America and the Caribbean and by FIUR from Universidad del Rosario. We thank Catalina Latorre and Mónica Ortegón for their participation in the field work and the questionnaire design. We gratefully acknowledge Laura Moreno, Jorge Pérez and Paul Rodríguez for their excellent research assistance; Luis Piñeros and Mauricio Castillo for the organization of the field work. We thank the participants on the IADB "Teenage Pregnancy" Workshop in Washington, the 8th PEP General Meeting in Dakar-Senegal, the NIP-LACEA meetings in Cali-Colombia and Medellín-Colombia, the LACEA 2010 conference in Medellín, the participants of the weekly seminars at Universidad de los Andes and Universidad del Rosario. We thank help and support of the Secretarías de Educación and Salud of the city of Bogotá and the comments and information provided by Ana Gómez from DNP and Hernando Sánchez from Acción Social.

The findings, recommendations, interpretations and conclusions expressed in this paper are those of the authors and not necessarily reflect the view of the Department of Economics of the Universidad del Rosario.

${ }^{\dagger}$ Department of Economics and CeiBA-Complejidad, Universidad del Rosario, Bogotá

${ }^{\ddagger}$ Department of Economics, Universidad del Rosario, Bogotá

${ }^{\S}$ Department of Economics and CeiBA-Complejidad, Universidad del Rosario, Bogotá
} 


\section{Introduction}

In recent years Conditional Cash Transfer programs (CCTs) have been implemented in many countries around the world; according to the World Bank between 1997 and 2008 the number of countries that have implemented CCTs increased from 2 to at least 29. Many of these CCTs have concentrated in increasing school enrolment and have shown to be useful for this purpose (see for example De Janvry et al., 2006 and Schultz, 2004). However, school attendance is not the only outcome one may want to affect to improve living conditions of young individuals around the world. Other outcomes such as those related to sexual behavior, drug taking or other risky behaviors should also be included in the list. The objective of this paper is to study the conditions that CCTs must satisfy in order to improve non education outcomes.

For this purpose we analyze the effect of two large scale education CCTs, implemented in Bogotá (Colombia), on teenage pregnancy. We use data from the ECSAE survey ${ }^{1}$ which was originally constructed for this project and gathers information on several aspects of sexual behavior of schooled teenagers in Bogotá as well as of socioeconomic conditions and information about the two education CCTs in place in Bogotá. Given that the two programs were designed differently, the differences in their effects on teenage pregnancy shed light on the conditions that these programs must fulfill in order to improve non education outcomes.

Although there has been controversy about the effects of teenage childbearing, we believe that for a middle-income country like Colombia there are gains from reducing teenage motherhood. $^{2}$ First, using data from developed countries the literature has found that although there is evidence that when proper identification of the relation is done the effects are smaller than those found in simple correlations the effects are still significant in many cases (Geronimus and Korenman, 1992; Geronimus, 1993; Hoffman et al., 1993; Angrist and Ewans, 1996; Levine and Painter, 2003; Holmlund, 2005; Hotz, Mulin and Sanders, 1997; Hotz, McElroy and Sanders, 2005). Second, there are important reasons to believe that the effects of teenage childbearing in developing countries may be different from those in developed countries. In particular, developed countries usually have programs to assist teenage mothers or other programs that reduce the costs associated to school attendance for teen mothers. This can result in low or negligible effects of teenage childbearing on schooling and employment of the adolescents or health and schooling of their children. In developing countries these programs and institutions are scarce so the negative consequences of teenage pregnancy may be more important. Moreover, particularly important for the case we study, Miller (2010) has shown that access to family planning methods in Colombia helped postponing the age of first birth and implied increasing investments in human capital.

The two main education CCTs implemented in Bogotá (Colombia) are Familias en Acción $(F A)$ and Subsidio Educativo (SE). Both programs target poor households, use the same

1. ECSAE stands for Encuesta Sobre el Comportamiento Sexual de Adolescentes Escolarizados en Bogotá (Survey About Sexual Behavior of Schooled Adolescents in Bogotá).

2. The main trends in teenage pregnancy in Latin America are summarized in Flórez and Núñez (2001) and Flórez and Soto (2008). These authors show the existence of high levels of teenage pregnancy rates, a negative correlation between teenage childbearing and human capital of mothers and strong correlations of teenage motherhood and socioeconomic results. 
metric to determine elegibility and are similar with respect to size of the subsidy, management and verification conditions. In both cases school attendance is a minimum requirement to receive the subsidy. The programs differ mainly in two crucial aspects: the assignment criteria and the performance requirements to comply with the program. ${ }^{3}$ Regarding the assignment criteria, $F A$ goes to the poorest households (SISBEN level 1) and $S E$ goes to the not so poor households (SISBEN level 2). ${ }^{4}$ Regarding the conditions to comply with the programs they both have some performance criteria but differ in their form. $S E$ requires enrolment in the following grade to continue receiving the transfer, so students must successfully end a year to continue in the program. This is particularly important for the case of pregnancy since in most cases a pregnant girl will not be able to successfully finish the year. On the other hand, in the case of $F A$ attending school is enough to receive the subsidy regardless of success in the previous year; this means that a girl that became pregnant in the previous year will continue receiving the subsidy if she repeats the year and complies with the program in all other aspects. However, FA gives to each student an important amount of money when they successfully end high school which constitutes a subsidy to finish high school. Both programs condition the transfer on being younger than 18 years, $S E$ gives money for only two years while $F A$ has not limit other than age.

The effects of these programs on school enrollment have been studied by Attanasio et al. (2010) and by Barrera et al. (2011). Attanasio et al. (2011) show that FA has been effective but restricts the evaluation to the rural Colombia which has very different conditions than the big cities. Barrera et al. (2011) evaluated the pilot of SE. The pilot was implemented in two of the twelve localities of the city and allowed for three possible ways of designing the program. The results show that this program can be effective to increase school enrolment and also show that the way the program is designed matters.

Even if these programs have positive effects on school attendance it is not obvious that they will have positive effect on non education outcomes. Since these programs also provide insurance to adolescents they may increase risky behaviors. To show this we use a simple model that characterizes adolescents' schooling and pregnancy decisions; according to our model an education CCT that only conditions on school attendance has an ambiguous effect on teenage pregnancy. We also show that linking the program renewal to school success or limiting the number of years in which the benefits of the program can be claimed resolves the ambiguity and implies that the CCT also helps reducing teenage pregnancy.

From the description of both programs and from our theoretical results we can expect to find that $S E$ reduces teenage pregnancy. The only prediction that can be made for the effect of $F A$ is that it is smaller than the effect of $S E$; an increase in teenage pregnancy as a result of $F A$ is also possible according to our theoretical results. This is precisely what our empirical results show: on average, $S E$ reduces teenage pregnancy rates while $F A$ has no average effect

3. They also differ in that $F A$ makes part of a broader program that also has a nutrition component grants additional money to families that have small children for nutrition purposes. It is important to note that when a household already makes part of the program the appearance of new children is not used to recompute the transfer the household receives. Consequently, if families understand the program, the nutrition component should not be an incentive to fertility.

4. SISBEN is the name of the Welfare program in the country. It is based on a socioeconomic index, that receives the same name, that is used to sort households into five SISBEN levels. Households in Levels 1 and 2 are the poorest, and households in level 1 are the poorest of the poor. 
on pregnancy rates. When the effect of both programs are disaggregated according to age and grade $S E$ continues to reduce pregnancy rates for some of the groups considered but $F A$ may reduce or increase pregnancy rates for some of the groups. The empirical results are in line with our theoretical results. Given that both programs are quite similar and that in our regressions we control for socioeconomic background, we can interpret this result as saying that incentives are crucial if one wants education CCTs to reduce teenage pregnancy rates or risky behaviors of adolescents. Barrera et al. (2011) have also shown that there are still several margins that should be considered to improve the efficiency of CCTs, our result goes in the same line as their result. They concentrate on the education outcomes (attendance and enrollment) of CCTs while our results concern non education outcomes.

Our empirical strategy allows the use of differences-in-differences methods to identify the effect of policies. Similarly to Duflo (2001), the identification strategy relies on intensity differences across schools in the implementation of the CCTs to define the treatment and the control group (high intensity and low intensity schools). We define cohorts to introduce the time dimension: the interviewed girls belong to the young cohort (after treatment) and their older sisters that attended the same school belong to the old cohort (before treatment). The comparison of the two cohorts allows us to show that the rate of schoolgirls which are pregnant or already mothers and attended high intensity $S E$ schools is reduced in two percentage points with respect to those attending low intensity $S E$ schools. For the case of $F A$ there is no difference between high intensity and low intensity $F A$ schools.

Recently three studies have investigated the effect of human capital policies on teenage pregnancy or on risky behaviors: Baird et al. (2010) using data from Malawi, Duflo et al. (2006) using data form Kenya and Black, Devereux and Salvanes (2008) using data from the US. They all show cases in which education CCTs or other policies to foster human capital have also reduced teenage pregnancy. However, as we also show with our simple model, this is not an obvious result. Since these programs also have insurance properties they may bring an increase in risky behaviors of adolescents. As our empirical results show, to have a robust CCT that increases school enrolment and reduces teenage pregnancy (and probably also other risky behaviors) the program must include incentives to school success. ${ }^{5}$

This paper is composed by seven sections. The first section is this introduction. Section 2 makes a detailed description of the education subsidies implemented in Bogotá. Section 3 presents a simple model that allows to capture the effects of the two programs. Section 4 presents the empirical strategy that we use to identify causal effects. Section 5 presents the data and relevant descriptive statistics. Section 6 presents results and robustness checks. Section 7 concludes.

\section{Education Conditional Cash Transfer programs implemented in Bogotá}

Bogotá is an interesting city to study the impact of educational policies that reduce the costs of human capital accumulation faced by individuals. The government of the city and the

5. Our paper is also related to the literature on the effect of economic incentives on teenage pregnancy, on this see Wolf, Wilson and Haveman (2001) and Lundberg and Plotnick (1995). 
national government have made large efforts to implement education policies that reduce school attendance barriers. In this section we describe the two education CCTs, Familias en Acción $(F A)$ and Subsidio Educativo $(S E)$, that are currently implemented in Bogotá. $F A$ is funded by the national government and $S E$ by the government of the city of Bogotá, however most of the administration of both programs is in the hands of the government of the city and the Education Office of the city plays an important role in administration and control of both programs.

Familias en Acción is the main Colombian CCT, it started in 2002 in rural areas and small cities and was extended massively to big cities in 2008. FA targets households that belong to the poorest population (SISBEN 1). ${ }^{6}$ Families in the program receive nutrition and school attendance subsidies; the nutrition subsidies are for children with less than 12 years and the education subsidies for children older than 12 years. Since the nutrition component targets children that do not belong to the population in our study we do not describe it; we must say that the design of the program avoids this component from becoming an incentive to teenage childbearing. The education component of the program gives to each household $\$ 35,000$ Colombian pesos per month per children with ages between 12 and 18 years old that attends 9th and 10th grades; for children attending 11th grade the subsidy is $14.3 \%$ higher. The education subsidy is conditional on a minimum daily school attendance of the adolescent; if this condition is satisfied the household will receive the subsidy until the child ends or drops out from high school. If the attendance condition is not satisfied the family loses the subsidy for the current period but in the following it can regain the benefit. Finally, $F A$ gives to students a lump-sum of $\$ 430,000$ Colombian pesos when they successfully finish high school. ${ }^{7}$

Subsidio Educativo was introduced in $2006^{8}$ targeting the poorest population of the city (SISBEN 1 and 2). The program has had two different phases, in 2006 and 2007 the program attended 45,000 beneficiaries, randomly chosen from 136,000 applicants, aged 18 years or less and enrolled in the official education system between 6th to 11th grades. In 2007 some new beneficiaries were accepted to keep the original number of 45,000. In 2008 the program was in place only to attend the students that entered the program in 2007 to replace those that left the program at the end of $2006 .{ }^{9}$ Since 2009 the program targets individuals in SISBEN 2 .

6. There are several differences in the way FA been implemented in Bogotá and in the rest of the country, the description here corresponds to the way it has been implemented in Bogotá.

7. In February of 2010, when our data collection process started, the exchange rate between Colombian pesos and US dollars was 1953 pesos per US dolar. This means that in that moment the $F A$ nutrition subsidy was equivalent to US $\$ 25.6$ for families of children between 0 and 6 years and of US $\$ 10.2$ for families with children between 7 and 12 years old. The subsidy per children older that 13 years attending school was equivalent to US $\$ 17.1$ and the lump-sum given at the end of high school was equivalent to US $\$ 220$.

8. In 2005 a small pilot was implemented, the program was extended based on a positive evaluation, see Barrera et al. (2011).

9. Recall that in 2008 the national government started to implement $F A$ in big cities; during this year $S E$ was not implemented due to the negotiations between the city and the national government about the implementation of both programs. 
$S E$ lasts for two years, in 2009 gave $\$ 35,000$ Colombian pesos ${ }^{10}$ per month per adolescent in the household. Payments are done each two months during the 10 months of the schooling year. The subsidy is implemented with a debit card that is given to the mother when the student is aged less than 16 years and directly to the student if she has more than 16 years. As with $F A$ there is a minimum daily school attendance requirement; unlike $F A$, if this minimum is not attained students loses definitively the subsidy. The renewal of $S E$ depends on successfully finishing the academic year.

$S E$ has a variant in which a subsidy to cover transportation costs is granted to students. But the amount of money that students receive and all the conditions not to lose the subsidy are the same as with the main variant. The main differences with the main variant are that all students attending public schools are eligible independent from social conditions and that the subsidy targets students that live more than 2 kilometers away from their school.

\section{A simple model to capture the effect of education Condi- tional Cash Transfer programs on teenage pregnancy}

According to the description of the two programs that make part of our study we need to characterize the effects of education CCTs on teen pregnancy that differ in two characteristics: the timing of implicit incentives and the the relation between performance and benefits claiming. We do this with a simple model.

Consider a population of mass one of girls who are attending high school in a given common grade, $g$. Time is discrete and is represented by $t \in\{1, \ldots, T\}$. Each girl's live spans $T$ period, all girls discount the future with a common factor $\beta$ but they differ in age, $a$, and in their desire to become mothers, $m$ ( $m$ represents the per year money equivalent utility of being a mother). We assume that $m \in[\underline{m}, \bar{m}], a \in[\underline{a}, \bar{a}]$ with $\underline{a}>0$ and $\underline{m}>0$ and let $f(a, m)$ represent the distribution function of girls of type $(a, m)$. Since all girls are in the same grade, they all have to complete the same number of additional years before finishing high school, this number of years is represented by $s$. A girl that does not finish high school will receive a per year wage $w$, a girl that finishes high school receives a per year wage $w+\delta$ (with $\delta>0$ ). If pregnant before ending high school, any girl faces a probability $p \in(0,1)$ of finishing high school but she will have to spend additional time $\sigma$ before graduation (this includes years repeated or time spent out side from school).

To introduce the education CCT program in this stage we make the most flexible assumption but conserve the main feature of this program: children or their families receive the subsidy as long as they are attending school. During high school girls receive a transfer of size $e_{t}$ in period $t$ conditional on attending school; let $\hat{e}$ represent the vector containing all the values of $e_{t}$.

Motherhood implies no other opportunity costs for girls besides those related to finishing high school. Accordingly, all girls that finish high school and are not already mothers will become mothers immediately after finishing high school. At age $a$ the continuation lifetime

10. With the February 2010 exchange rate this is equivalent to US $\$ 17.9$ 
utility of a girl that finishes high school before becoming a mother will be

$$
u^{a, m}=\sum_{t=a+s+1}^{T} \beta^{t-a}(w+\delta)+\sum_{t=a}^{a+s} \beta^{t-a} e_{t}+\sum_{t=a+s+1}^{T} \beta^{t-a} m .
$$

The life time utility of a girl that becomes pregnant during high school at time $\tau$ is

$$
\begin{aligned}
v^{a, m}(\tau)= & p\left[\sum_{t=a+s+\sigma+1}^{T} \beta^{t-a}(w+\delta)+\sum_{t=a}^{a+s+\sigma} \beta^{t-a} e_{t} .\right] \\
& +(1-p)\left[\sum_{t=a+\tau+1}^{T} \beta^{t-a} w+\sum_{t=a}^{a+\tau} \beta^{t-a} e_{t}\right] \\
& +\sum_{t=a+\tau+1}^{T} \beta^{t-a} m
\end{aligned}
$$

Consequently a girl will become pregnant at age $a+\tau<a+s$ before ending high school if $v^{a, m}(\tau) \geq u^{a, m}$, otherwise she will wait until finishing high school to become a mother. Let $\tau^{a, m}$ be the optimal time to get pregnant for a girl of type $(a, m)$; with a slight abuse of notation let $v^{a, m}=v^{a, m}\left(\tau^{a, m}\right)$. Monotonicity properties of $v^{a, m}$ allow to prove that for any age $a$ there will be a girl that will be indifferent between becoming a mother before finishing high school and waiting; this marginal girl is defined by

$$
v^{a, m}=u^{a, m} .
$$

We denote the type of the marginal by $\widetilde{m}(a, \hat{e})$. The rate of age $a$ girls with age attending grade $g$ that will become pregnant before finishing high school is given by

$$
r_{g}^{a}(\hat{e}) \equiv \int_{\widetilde{m}(a, \hat{e})}^{\bar{m}} f(a, m) d m
$$

where $\hat{e}$ is a vector containing all the $e_{t}$ and it summarizes the characteristics of the CCT. The rate of girls attending grade $g$ that will become pregnant before finishing high school is given by

$$
r_{g}(\hat{e}) \equiv \int_{\underline{a}}^{\bar{a}} \int_{\widetilde{m}(a, \hat{e})}^{\bar{m}} f(a, m) d m d a .
$$

Any policy that increases $\widetilde{m}$ will reduce $r_{g}$ and $r_{g}^{a}$. To show how alternative ways of designing the CCTs affect teenage pregnancy we consider particular cases chosen to match the main characteristics of the two Colombian CCTs we analyze in this paper. These are characteristics that could be considered to be included in any other CCT.

i. The effect of an education CCT that only conditions on school attendance on teenage pregnancy: Suppose $\beta=1$ and $e_{t}=e$. Note that we are assuming that a girl that becomes pregnant receives the subsidy every year until she finishes high school if she is lucky to be able to finish; this means that pregnancy does not make girls leave school temporarily and that $\sigma$ only represents repeatency. 
All girls with $m<e$ will wait until $a+s$ to become pregnant since for them $v^{a, m}(\tau)$ is increasing in $\tau$. For girls with $m>e, v^{a, m}(\tau)$ is decreasing in $\tau$; this means that any girl that wants to become a mother before $a+s$ will do so at age $a$ (i.e. $\tau^{m, a}=0$ ). Among girls for who $m>e$ there will be some that become pregnant before $a+s$ and some that wait. Using this to write $v^{a, m}(\tau)$, equation (1) implies that

$$
s \widetilde{m}^{i}(a, e)=[(1-p)(T-a-s-1)+p \sigma] \delta-[s-p(s+\sigma)](w-e)
$$

Since $\widetilde{m}^{i}$ decreases with $a$ for a given age, girls with higher $m$ will become pregnant more frequently than girls with low $m$ and for a given $m$ older girls will become pregnant more frequently. Let $r_{g}^{a, i}$ represent the rate of girls that become pregnant under this type of program; as before $r_{g}^{a, i}$ is a function of $e$.

From equation (4)

$$
\frac{\partial}{\partial e} \widetilde{m}^{i}(a, e)=[s-p(s+\sigma)] / s
$$

which shows that, starting from a situation in which there is no CCT $(e=0)$ introducing a $\mathrm{CCT}$ conditional on education attendance will reduce the teenage pregnancy rate if

$$
\frac{s}{s+\sigma}>p
$$

The CCT will be effective for teenage pregnancy reduction if the probability of finishing high school is low or if $\sigma$ is low. In both cases the penalty for teenage pregnancy is big. When $p$ is low girls perceive high opportunity costs of pregnancy; when $\sigma$ is low girls perceive low colateral economic benefits or prolonged time at school since they will receive the subsidy for a short additional period. This shows that an education CCT does not necessarily reduce teenage pregnancy. As we will show now, CCTs can be designed (in theory) to unambiguously reduce teenage pregnancy.

ii. The effect of limiting the number of years CCT education program: Suppose that $\beta=1$ and that $e_{t}=e>0$ for $a \leq t \leq a+s$ and $e_{t}=0$ for $t>a+s$. As in the previous case girls with $m<e$ will wait until $a+s$ to become pregnant. Among girls with $m>e$ there will be a marginal girl that will be indifferent between waiting or becoming pregnant at age $a$ :

$$
s \widetilde{m}^{i i}(a, e)=[(1-p)(T-a-s-1)+p \sigma] \delta-(s-p s)(w-e)+p \sigma w .
$$

In this case

$$
\frac{\partial}{\partial e} \widetilde{m}^{i i}(a, e)=1-p>0 .
$$

Accordingly, introducing an education CCT that conditions benefit claiming on performance, unambiguously reduces teenage pregnancy. Moreover

$$
\widetilde{m}^{i}(a, e)-\widetilde{m}^{i i}(a, e)=-p \sigma e / s<0
$$

so $\widetilde{m}^{i i}>\widetilde{m}^{i}$. Let $r_{g}^{a, i i}$ represent the rate of girls that become pregnant under this type of program; as before $r_{g}^{a, i i}$ is a function of $e$.

iii. The effect of conditioning renewal on performance: Suppose now that girls stop receiving the transfer if they fail to successfully finish the academic year and that $e_{t}=e>0$ 
for all years in which the girls receive the subsidy. In this case girls that will get pregnant at age $a$ will not receive any benefit from the program. This implies that

$$
s \widetilde{m}^{i i i}(a, e)=[(1-p)(T-a-s-1)+p \sigma] \delta-[(s-p s) w-s e]+p \sigma w
$$

In this case

$$
\frac{\partial}{\partial e} \widetilde{m}^{i i i}(a, e)=1>0 .
$$

so that introducing a subsidy with the stated rules reduces teen pregnancy. Moreover

$$
\widetilde{m}^{i i i}(a, e)-\widetilde{m}^{i i}(a, e)=p e>0
$$

so that conditioning the renewal of the subsidy on school success reduces teenage pregnancy rates. Similar to the previous two cases, let $r_{g}^{a, i i i}$ represent the rate of girls that become pregnant under this type of program; as before $r_{g}^{a, i i i}$ is a function of $e$.

iv. The effect of the timing of incentives: We need to compare a program with the structure of any of the three programs considered above (i, ii or iii) but that delays some of the economic benefits for until end of highschool. This case need no formalization since it is clear that if girls have preference for the future $(\beta<1)$, or any sort of myopia any alternative to the previous three which leaves some resources $E$ until the end of highschool and keeps constant the financial costs of the program will have higher pregnancy rates than the original program. Note that in this case we are not making any implication about the effect of the program and attendance decisions as the ones analyzed by Barrera et al. (2011).

To summarize we have shown that CCT programs that condition renewal on academic performance will have higher pregnancy rates than those that do not condition on academic performance. Programs in which there is a limit on the number of years in which the benefits can be claimed have lower pregnancy rates than those in which there is no limit but still reduce pregnancy rates. This means that

$$
r_{g}^{a, i i i}(e)<r_{g}^{a, i i}(e)<r_{g}^{a, i}(e) .
$$

If on top of the conditions of programs in i, ii or iii, some resources are given to the girls only after they finish highschool the pregnancy rates will be higher than those the specific program considered with out delaying resources. This means that the form the conditions take is important for teenage pregnancy; tighter conditions imply lower pregnancy rates and delaying benefits will increase pregnancy rates if girls exhibit preference for the future or myopia.

\section{Empirical strategy}

In Section 3 we showed that education CCTs may affect teenage pregnancy and that the characteristics of the programs may affect this relation. Let the probability of becoming pregnant for a girl of age $a$, attending grade $g$ in school $j$ under a CCT with characteristics represented by $\hat{e}$ be given by

$$
\operatorname{Prob}\left[u^{a, m} \geq v^{a, m}\right] \equiv q(\hat{e}, a, j, g) .
$$


Equation (2) suggest that an empirical exercise to capture the differential effects of two education CCTs on teenage pregnancy must estimate

$$
\Delta q(\hat{e}, 0)=q(\hat{e}, a, j, g)-q(0, a, j, g) .
$$

Estimating the effects of different configurations of $e$ is difficult. Instead, we will identify the effect of the two education CCTs that have been implemented in the previous years in Bogotá. Consider then the following probability

$$
\operatorname{Prob}\left[u^{a, m} \geq v^{a, m}\right] \equiv q(t, a, j, g)
$$

where $t$ indicates whether the girl was treated by one of the two programs $t \in\{F A, S E\}$. We can then estimate the equation

$$
\Delta q(t, 0)=q(t, a, j, g)-q(0, a, j, g) .
$$

Since the programs are similar enough in most characteristics we can attribute the difference in the estimates to differences in the form in which they are designed.

According to equation (7), when comparing two CCTs, one that conditions renewal on performance and another that does not, we can expect to find a lower pregnancy rate under the first. As we explained in Section $2 S E$ conditions renewal on performance and $F A$ does not. Moreover, our model also shows that a program that does not have a binding limit on the number of years in which the benefits of program can be claimed may have a positive effect on teenage pregnancy rates. Although $F A$ includes this type of condition, in practice, most girls in Colombia end high school before 18 years so that the rule might not bind. Consequently we expect that $\Delta q(F A, 0)>\Delta q(S E, 0)$; we can also expect $S E$ to reduce teenage pregnancy and for $F A$ we may expect to have positive and negative effects depending on whether the age limit is binding or not.

The treatment variables are defined at the school level. We consider a treatment given by a dummy variable, so that we split schools in two groups: schools with high treatment and schools with low treatment. The indicator variable for treatment $t, t \in\{\mathrm{FA}, \mathrm{SE}\}$ in school $j$ is defined as follows:

$$
T_{t j} \equiv 11\left[\pi_{t j}>\bar{\pi}_{t j}\right]
$$

where $\pi_{t j}$ denotes the proportion of girls in school $j$ that receive the treatment $t$ and $\bar{\pi}_{t j}$ denotes the average proportion of girls receiving treatment $t$ across schools.

Since we have cross-section data we do not have information before and after the treatment for the same individuals. Instead, in the same vein of Duflo (2001), we define two cohorts which differ in their likelihood of having been treated. These two cohorts allow us to use difference-in-differences strategy to identify the causal effect. In our paper the two cohorts are constructed using information provided by the girls about the older sisters that both studied in the same school and did not drop out from school. This strategy allows us to control for school and household unobservables that do not vary across time.

We use the difference in difference strategy to identify the causal effect of education policies on teenage pregnancy. Since we have two treatments, to fully identify the causal 
effect of those treatments we estimate the following equation:

$$
\begin{aligned}
Y_{i j}= & \alpha+\alpha_{C} C_{i}+\alpha_{F A} T_{F A j}+\alpha_{S E} T_{S E j}+\alpha_{F S} T_{F A j} T_{S E j}+ \\
& \beta_{F A} T_{F A j} C_{i}+\beta_{S E} T_{S E j} C_{i}+\beta_{F S} T_{F A j} T_{S E j} C_{i}+ \\
& \gamma^{\prime} X_{i j}+\delta^{\prime} Z_{j}+\varepsilon_{i j}
\end{aligned}
$$

where $Y_{i j}$ is a dummy variable that takes value 1 when woman $i$ who attends or attended school $j$ has had at least one child during teenage (between 14 and 19 years old) and value 0 otherwise. The cohort to which woman $i$ belongs is given by $C_{i} ; C_{i}$ takes value 1 if she is in the young cohort (women aged 14 to 19 who are still attending school) and value 0 if she is in the old cohort (women aged 19 to 32 and already out from school). ${ }^{11} T_{t j}$ identifies whether school $j$ is a high intensity treatment school under program $t \in\{F A, S E\}$ according to equation (9) above; $X_{i j}$ is a vector of individual characteristics; $Z_{j}$ is a vector of school characteristics, including fixed effects by regions of Bogotá. ${ }^{12}$ This equation corresponds to a linear version of equation (8) but we allow the possibility of additional controls to include individual and school characteristics that do not appear in the model of Section 3.

Our main parameters of interest are $\beta_{F A}, \beta_{S E}$ and $\beta_{F S}$. As already explained the identification strategy corresponds to a difference-in-difference approach taking advantage from the existence of school with high and low intensity treatment. The causal effect of each treatment will be identified by the estimation of coefficients $\beta_{t}, t \in\{F A, S E\}$. The causal effect of the interaction between any pair of treatments above and beyond the causal effect of each treatment will be identified by the estimation of coefficient $\beta_{F S}$. Furthermore, we will check whether there are heterogeneous effects across grades, ages and, grades and ages combined. We do so by including interactions in equation (10).

As usual, there are several challenges to credibly identify causal effects using this approach. The key identifying assumption behind the differences-in-differences approach is that selection biases are linear and time-invariant. In other words, if there is any difference in the pretreatment period, this difference should be stable across time. In order to test the identifying assumption we run a placebo regression where we only include data from the old cohort. We split data in two groups by age. Younger old sisters are included in one cohort and older old sisters in the other one. There must be no effect of treatments across sisters in order to credibly identify causality estimating equation (10).

A second challenge for our approach comes from the fact that we sub-estimate the likelihood of teenage pregnancy of the younger cohort. The reason is that, unlike the older cohort, not all individuals in the younger cohort have finished their teenage years. We tackle this problem by controlling for individual age. The younger the girl the less likely teenage pregnancy. Introducing age as a covariate should correct the expected pregnancy rate for each cohort.

Another challenge for identifying causal effects comes from the definition of cohorts. On the one hand, the older cohort must strictly be previous to the treatment in order to be useful

11. Recall that women in the young cohort correspond to the girls interviewed in our field work and women in the old cohort correspond to their sisters.

12. Regions in Bogotá are called localidades. 
to identify the causal effect. Since $S E$ started in 2005 and $F A$ in 2008, some women from the old cohort between 19 and 22 years old have some probability to have been treated. This fact may bias our results. If any, the bias will be downwards and make our estimates a lower bound of the true estimator. On the other hand, if we only include sisters older than 22 in the old cohort we may end up comparing siblings that are not so comparable. Acknowledging these possible biases in our exercises we make a robustness check in which we run the same regressions restricting the sample excluding the youngest and the oldest women from the old cohort. ${ }^{13}$ In addition, since girls in the young cohort may be linked to more than one older sister, we make a robustness check in which we restrict the sample to include only the youngest old sister. This is a kind of acid test to our results because of the downward bias we explained above.

A fourth challenge to our estimates comes from our definition of the treatment. Our treatment dummies are based on an ad-hoc threshold (the mean proportion of treated girls across schools) to separate high intensity and low intensity treatment schools. To be sure that our results are not driven by this ad-hoc definition we use alternative definitions of the treatment dummies based on different thresholds. To test whether our findings are driven by the threshold we run the same regressions by using different percentiles. Our results must be robust to use different thresholds.

We further check whether the fact of solely including sisters in the old cohort that did not dropped out from school plays a role in our results. As a robustness check we make the same regression including dropping out sisters. Finally, all regressions are performed clustering residuals at the region level (localidad). To check robustness of standard residuals we bootstrap errors while clustering at the region level.

Holmlund (2005) has shown that in fertility studies the sibling approach may have the problem of not recognizing possible changes in time for the household. We believe that our restrictions on cohorts help reducing this possible source of bias. The cost of doing so is that we reduce the external validity of our results. Focusing on cohorts that studied in the same school may reduce the validity of results applied to migrating households. Children from migrating households may have changed from high-intensity treated to low-intensity treated schools back and forward.

\section{$5 \quad$ Data and descriptive statistics}

As explained in the introduction the empirical analysis uses information from the ECSAE Survey. This is an original survey of boys and girls enrolled in 273 schools in Bogotá. ${ }^{14}$ The field work to construct this data base took place between the months of February and April 2010. The survey interviewed adolescents between 14 and 19 years enrolled in the three last years of high school ${ }^{15}$ in public and private schools. The sample has been selected with a

13. To maintain control on household and school fixed effects we also exclude their respective sisters in the young cohort.

14. The number of schools visited amounts to roughly one fourth of all schools offering 9th, 10th and 11th grades in the city.

15. In Colombia these correspond to 9 th, 10 th and 11 th grades. 
probability proportional to population size estimated from Bogotá's 9th to 11th enrollment for the year 2009 so that the survey is representative at the regional level (localidades). For the purpose of this study only the data from girls is relevant; the final data base contains information of 21.262 girls.

The main information of the data base for the purpose of this study is that about teenage pregnancy and fertility and about the incidence of the CCTs. The survey also collected socioeconomic information, information on mother and sisters' fertility and education, and knowledge and use of contraceptive methods. In this section we discuss the information that is used to evaluate the effect of education policies on teenage pregnancy. For the purpose of this paper we have also merged to the data base information about school facilities and school quality that comes from administrative records of the Colombian government. Finally we have also merged to the data base information about crime incidence and neighborhood safety at the regional level.

In order to evaluate the impact of the CCTs implemented in Bogotá on teenage pregnancy, we take advantage of the information collected about older sisters of the interviewed girls. This information allows us to identify sisters' childbearing, age, age at the first child was born, and if the sister studied in the same school the last year attended. From the 21.262 interviewed girls we recovered information on childbearing, age and age at the first child for 3.598 sisters. As was stated in the empirical strategy section we use the sister's information to build an old cohort which could be comparable with the interviewed girls, but who were less likely to be affected by any cash transfer in Bogotá. The old cohort is composed by sisters that comply all the following conditions: i. 19 to 32 years old, ii. studied in the same school as their interviewed sisters and iii. did not dropped out from high school. At the end of this process we finished with a sample of 1.251 sisters $(53.35 \%)$ in the old cohort and 1.094 interviewed girls (46.65\%) in the young cohort (see Tables 2 and 3). Those tables also report frequencies of girls across treated and non-treated schools for both $F A$ and $S E$.

In what follows we present some descriptive statistics on teenage pregnancy, individual characteristics, school quality and conditions of the neighborhood. We compare average characteristics across cohorts (Table 4) and treatment and control groups for both cash transfers (Tables 5 and 6$).{ }^{16}$ The first three columns of each of those tables provide information on the total sample including recovered information on sisters. The last three columns report information on the sub-sample used for the econometric exercise. In Table 4 we report data on the interviewed girls (young cohort) and their older sisters (old cohort). In the full sample (column 1) the interviewed girls are characterized by a teenage pregnancy incidence of about $3 \%$, their age is around 15 years old in average, the average household has 5.26 members, their mothers have 3.24 children in average and $24 \%$ of the girls study in private schools. The other variables describe school quality (larger index means higher quality), distance to the nearest bus station, neighbor security (theft number by thousand inhabitants) and standard of living (larger index report better standard of living). ${ }^{17}$

16. Table 1 reports the definition of all variables used in the empirical exercise.

17. Our school quality index is the 5 th grade math average score in the SABER examination (a general public examination implemented by the national government). The living standard index weights dwelling conditions and socioeconomic achievements (parents' education) of the interviewed girls' family. 
Columns 1, 2 and 3 from Table 4 show that girls in both cohorts, in the original data base, differ in important ways in several characteristics. Columns 4, 5, and 6 show that the methodology explained in the previous section makes both cohorts more similar in several respects, including household' standard of living, size and home rooms, and school's number of pupils per teacher and proportion of pupils in private schools. This reduces the concerns of Holmlund (2005) for our empirical analysis.

Comparing treated and control groups for both programs we can see that, in average, these groups are different. For both programs, girls in both cohorts from treated schools (high intensity) come from poorer and bigger households, study in schools with lower quality and live in regions exposed to less crime rates than girls from the control schools (low intensity). Differences in girls' age are not significant (see Tables 5 and 6). Differences are larger for $F A$ than for $S E$, which reflect the fact that $F A$ attends the poorest households.

Table 7 shows the average incidence of pregnancy by cohort and treatment status. Consider first the effect of $S E$ in the second panel. Notice that the treated schools have higher teenage pregnancy incidence than control schools before the treatment is implemented $(7.4 \%$ against 3.5\%). After the treatment both treatment and control schools end up with similar pregnancy prevalence $(2.5 \%$ and $2.3 \%$, respectively). The teenage pregnancy incidence decreases 1.2 percentage points in the control group and 4.9 percentage points in the treatment group. Without controlling for observable covariables the causal effect of $S E$ on teenage pregnancy amounts to a reduction of 3.7 percentage points. A similar analysis shows that $F A$ seems to have caused an increase in teenage pregnancy of 2.2 percentage points. ${ }^{18}$

\section{$6 \quad$ Results and robustness checks}

The model in Section 3, summarized in equation (7), predicts that an education CCT program that does not condition on performance and does not limit the number of years in which the program benefits can be claimed will cause higher pregnancy rates than alternative programs in which these two conditions are included. This is explained by the insurance characteristics of education CCTs that only condition on school attendance. Moreover conditioning renewal on school success is more effective to reduce teenage pregnancy than limiting the number of years in which the subsidy can be claimed. As we will show now, our empirical results are in line with the predictions of the model.

All results and robustness checks are in the Appendix. In Table 8 we report regressions without controls. In the first two columns we include a single treatment. The interaction between cohort and treatment gives an initial estimate about significance of causal effects reported in Table 7. In column 1 we report results of the program Familias en Acción (FA). In column 2 we report results of the program Subsidio Educativo $(S E)$. The SE program seems to reduce teenage pregnancy (column 2) and $F A$ seems to increase it (column 1). However, once we make estimations including both programs and school fixed effects, $S E$ still seems to reduce teenage pregnancy but $F A$ seems to have no effect, on average (see column 3 ).

18. Additional descriptive statistics are reported in Tables $19-23$ where we report covariates by treatmentcohort and frequencies by grade and grade-age. 
In Table 9 we report estimates of equation (10). ${ }^{19}$ In column 1 we report results with no controls. In the following columns we progressively introduce controls at the individual (age), household (size, number of mother's children, socioeconomic index, and number of rooms at home), school (student-teacher ratio, quality, private/public and distance to public transport system) and region (crime rates, fixed effects) level, respectively. First of all notice that, the causal effect of both programs are robust to all specifications. Second, $F A$ has no effect on teenage pregnancy on average and $S E$ causes a reduction of teenage pregnancy. Since the outcome variable is a dummy the estimation of the effect of $S E$ cannot be interpreted as the marginal effect. In Table 10 we report marginal effects obtained from probit estimations; the results are consistent with those in Table 9 and show that $S E$ reduces the incidence of teenage pregnancy in around two percentage points and that $F A$ has no effect.

As we have argued in the theoretical section age affects the way in which the CCTs affect girls' decisions; grade may also affect their decisions. To look at this, we ran the same specification in equation (10) adding interactions with grade and age. Table 11 shows that the effect of the programs on pregnancy varies across both dimensions. It seems that $S E$ program reduces pregnancy in all grades. All coefficients are negative but only 10th grade's is significant. It also seems that the non significant effect of $F A$ is the net effect of two opposite effects. The $F A$ program seems to increase pregnancy among girls in 10th grade and reduce that of girls in 11th grade. The first effect is significant and the second is not.

Similar results are obtained when we look at heterogeneous effects across age (see table 12). The $S E$ program reduces teenage pregnancy at all ages ${ }^{20}$ and the effects on 14,15 and 17 years old girls are significant. The $F A$ program has opposite effects depending on age: it increases pregnancy of 16 years old girls and reduces pregnancy of 18 years old girls. A full set of interactions between age and grade are reported in Table 13. The reducing effect of $S E$ program on pregnancy is negative across both grade and age but only significant for 15 years old girls in all grades. Regarding $F A$, age plays an important role: relatively old girls (17 and 18) that receive the transfer reduce their pregnancy. But pregnancy of 16 years old girls attending 10th grade increases when they receive the transfer.

In Tables 14, 15 and 16 we report the robustness checks corresponding to the challenges mentioned in the empirical strategy section. In column 2 Table 14 we report results of the placebo treatment. We split the sample of the old cohort in two: younger sisters (19-22 years old) and older sisters (23-32 years old). We must have no effect in order to validate the identifying assumption of our approach. As we can see, treatment has no effect on older cohorts, so we can credibly attribute our findings to the CCTs. In column 3 we bootstrap errors. In Column 4 we include in the regression sisters that dropped out from school. And in column 5 we run the regressions keeping the younger sister the interviewed girls have in the old cohort. Results are robust to all specifications.

In Table 15 we report a sequence of regression in which we test whether our results are robust to the definition of cohort. In column 1 we report our benchmark regression. In

19. In Table 18 we report estimates of all coefficients. It can be seen that controlling for age makes the cohort coefficient change sign. This means that girls from the young cohort are more likely to become teenage mothers than girls from the old cohort.

20. Only the effect on 18 years old is positive but not significant. The standard error is four times bigger than the coefficient. 
column 2 we exclude the younger sisters from the old cohort. ${ }^{21}$ In column 3 we exclude the older sisters from the old cohort. In column 4 we exclude older sisters and younger interviewed girls with the aim to have girls of similar age in both cohorts. Our results hold in all regressions.

Finally, in Table 16 we report results obtained when we change the threshold that defines the treatment variable. We use different percentiles ranging from 30th percentile to 50th percentile to test whether the choice of an arbitrary threshold drives the result. The causal effect is robust to thresholds changes.

The theoretical prediction of our model about the link between CCTs and teenage pregnancy can be seen from the average effects in our benchmark estimation. Our empirical findings show that $S E$ has a negative significant effect on teenage pregnancy while $F A$ has a null effect. The renewal of $S E$ is conditioned on school performance since the girl (or her family) will only receive the subsidy if she gets enroled in the following year. $F A$ does not condition renewal on performance but limits the number of years in which the subsidy can be claimed since only families of girls younger than 18 years can claim the subsidy. However, since most girls are young enough to afford spending one more year in school and still not losing the subsidy the limit is not binding. This can be seen from Table 23 where it is shown that for each grade more than half of the girls will receive during one more year the subsidy if they have to repeat a year since they will still finish high school before becoming 18 years old. The heterogeneous effects also support these findings. For none of the groups we have considered (disaggregated by age and grade) we have found a positive and significant effect of $S E$. However, for $F A$ we found positive and negative significant effects for particular groups of girls according to their age and the grade in which they are enrolled.

\section{$7 \quad$ Final remarks}

The results in this paper show that not all education Conditional Cash Transfer programs (CCTs) reduce teenage pregnancy. To show this we compared the effect of two CCTs implemented in Bogotá, Colombia, i.e., Familias en Acción and Subsidio Educativo. Our main finding is that Subsidio educativo causes a seizable reduction on teenage pregnancy while Familias en Acción has no effect. Even though our data does not allow to identify the specific channel through which CCTs reduce teenage pregnancy, the main differences between the CCTs we have considered are the performance condition and that $F A$ conditions some benefits on successfully finishing high school. Our results can be interpreted as saying that conditions on academic performance provide girls incentives to reduce pregnancy and that delaying the rewards of the programs reduce these incentives.

These results show that carefully designing education CCTs is crucial to guarantee that non education outcomes also improve or at least they do not worsen. Recently a discussion about the benefits of CCTs for education outcomes in the urban world has started; the benefits of these programs are challenged (compared to what happens in the rural world). Policy makers start to be concerned with dimensions different from school attendance in the

21. We also exclude their sisters in the other cohort in order to maintain the siblings approach. 
urban regions of many middle income countries. Our results show that the CCTs may still be valid but they should be conditioned in variables different than simple school attendance.

In this point it is important to note that the conditions that are needed to reduce teenage pregnancy may be detrimental for other purposes; for example Barrera et al. (2011) discuss that delaying rewards until the end of high school may help increase attendance to higher education since that reduces resources constraints that may affect the capacity to pay for starting costs in higher education. It is also possible that in a world in which students face psychological costs of attending school including performance conditions may discourage some students from attending school. These elements make part of the trade offs that must be solved for a good policy design. More research is needed to fully understand the effects of these policy elements. 


\section{A Tables}

Table 1. Variable glossary

\begin{tabular}{|c|c|}
\hline Variable & Definition \\
\hline Children & Number of mother's children \\
\hline Cohort & Identifies cohort, 1: Interviewed girls, 0: Sisters of interviewed girls \\
\hline Distance & Distance of school to nearest Transmilenio station \\
\hline$F A$ & Conditional cash transfers granted by Familias en Acción \\
\hline HH Size & Household size including the student \\
\hline Motorcycle theft & Motorcycle theft rate (one per thousand inhabitants) by locality \\
\hline Person theft & Thefts to persons rate (one per thousand inhabitants) by locality \\
\hline Private & 1 if she studies in a private school \\
\hline Rooms & $\begin{array}{l}\text { Number of rooms in the student's house excluding } \\
\text { kitchen, bathrooms or garages }\end{array}$ \\
\hline Sch-quality & Average math results of students in 5 year of primary school 2009 \\
\hline$S E$ & Conditional cash transfer granted by SED \\
\hline Standard of living & $\begin{array}{l}\text { Socioeconomic Index that includes sanitary type, } \\
\text { overcrowding, house's floor material and parents' education }\end{array}$ \\
\hline Students-teacher & Students-teacher relationship (2004 for sisters, 2008 for interviewed) \\
\hline
\end{tabular}


Table 2. Treatments Frequency: Percentage

\begin{tabular}{lrrrrr}
\hline \hline \multirow{2}{*}{ Total } & \multicolumn{2}{c}{ Fam. Acción $(F A)$} & \multicolumn{2}{c}{ Subs. Educ. $(S E)$} \\
& & Control & Treated & Control & Treated \\
\hline Old Cohort & $53.35 \%$ & $37.14 \%$ & $16.20 \%$ & $30.32 \%$ & $23.03 \%$ \\
Young Cohort & $46.65 \%$ & $32.92 \%$ & $13.73 \%$ & $26.40 \%$ & $20.26 \%$ \\
Total & $100.00 \%$ & $70.06 \%$ & $29.94 \%$ & $56.72 \%$ & $43.28 \%$ \\
\hline \hline
\end{tabular}

See Table 1 for the meaning of each variable

Table 3. Treatments Frequency: number of pupils

\begin{tabular}{|c|c|c|c|c|c|}
\hline & \multirow{2}{*}{ Total } & \multicolumn{2}{|c|}{ Fam. Acción (FA) } & \multicolumn{2}{|c|}{ Subs. Educ. (SE) } \\
\hline & & Control & Treated & Control & Treated \\
\hline Old Cohort & 1251 & 871 & 380 & 711 & 540 \\
\hline Young Cohort & 1094 & 772 & 322 & 619 & 475 \\
\hline Total & 2345 & 1643 & 702 & 1330 & 1015 \\
\hline
\end{tabular}

See Table 1 for the meaning of each variable 
Table 4. Descriptive Statistics by Cohort

\begin{tabular}{|c|c|c|c|c|c|c|}
\hline & \multicolumn{3}{|c|}{ Total $(\mathrm{n}=24860)$} & \multicolumn{3}{|c|}{ Sample $(\mathrm{n}=2345)$} \\
\hline & Young & Old & Difference & Young & Old & Difference \\
\hline Pregnancy & 0.03 & 0.03 & $0.00^{* *}$ & 0.02 & 0.05 & $-0.03^{* * *}$ \\
\hline Age & 15.41 & 19.23 & $-3.82^{* * *}$ & 15.50 & 21.82 & $-6.32^{* * *}$ \\
\hline Standard of living & 23.16 & 22.55 & $0.61^{* * *}$ & 23.03 & 22.90 & 0.13 \\
\hline HH Size & 5.26 & 5.72 & $-0.46^{* * *}$ & 5.58 & 5.66 & -0.08 \\
\hline Children & 3.24 & 3.70 & $-0.46^{* * *}$ & 3.59 & 3.72 & $-0.13^{*}$ \\
\hline Rooms & 4.10 & 4.22 & $-0.12^{* * *}$ & 4.30 & 4.31 & -0.01 \\
\hline Students-teacher & 27.02 & 30.71 & $-3.69 * * *$ & 27.04 & 30.55 & $-3.51^{* * *}$ \\
\hline Sch-quality & 325.47 & 325.01 & 0.46 & 330.63 & 330.18 & 0.45 \\
\hline Private & 0.24 & 0.22 & $0.02^{* * *}$ & 0.26 & 0.25 & 0.01 \\
\hline Distance & 2110.78 & 2135.72 & -24.94 & 1943.59 & 1981.26 & -37.67 \\
\hline Person theft & 1.42 & 0.77 & $0.65 * * *$ & 1.46 & 0.82 & $0.64 * * *$ \\
\hline Motorcycle theft & 0.13 & 0.15 & $-0.02^{* * *}$ & 0.14 & 0.17 & $-0.03^{* * *}$ \\
\hline
\end{tabular}

Two tailed significance level: ${ }^{* * *} \mathrm{p}<0.001,{ }^{* *} \mathrm{p}<0.05,{ }^{*} \mathrm{p}<0.1$.

See Table 1 for the meaning of each variable.

Table 5. Descriptive Statistics by Treatment Status:

Subsidio Educativo (SE)

\begin{tabular}{lrrrrrr}
\hline \hline & \multicolumn{3}{c}{ Total $(\mathrm{n}=24860)$} & \multicolumn{3}{c}{ Sample $(\mathrm{n}=2345)$} \\
& Treated & Control & Difference & Treated & Control & Difference \\
\hline Pregnancy & 0.03 & 0.02 & $0.01^{* * *}$ & 0.05 & 0.03 & $0.02^{* * *}$ \\
Age & 15.93 & 15.96 & -0.03 & 18.81 & 18.92 & -0.11 \\
Standard of living & 22.31 & 23.71 & $-1.40^{* * *}$ & 21.93 & 23.75 & $-1.82^{* * *}$ \\
HH Size & 5.43 & 5.24 & $0.19^{* * *}$ & 5.78 & 5.50 & $0.28^{* * *}$ \\
Children & 3.43 & 3.21 & $0.22^{* * *}$ & 3.93 & 3.45 & $0.48^{* * *}$ \\
Rooms & 3.97 & 4.24 & $-0.27^{* * *}$ & 4.09 & 4.47 & $-0.38^{* * *}$ \\
Students-teacher & 28.22 & 26.97 & $1.25^{* * *}$ & 29.18 & 28.71 & 0.47 \\
Sch-quality & 315.61 & 333.88 & $-18.27^{* * *}$ & 317.51 & 340.22 & $-22.71^{* * *}$ \\
Private & 0.00 & 0.44 & $-0.44^{* * *}$ & 0.00 & 0.45 & $-0.45^{* * *}$ \\
Distance & 1911.50 & 2284.16 & $-372.66^{* * *}$ & 1783.96 & 2100.84 & $-316.88^{* * *}$ \\
Person theft & 1.08 & 1.53 & $-0.45^{* * *}$ & 0.97 & 1.23 & $-0.26^{* * *}$ \\
Motorcycle theft & 0.12 & 0.14 & $-0.02^{* * *}$ & 0.14 & 0.16 & $-0.02^{* * *}$ \\
\hline \hline
\end{tabular}

Two tailed significance level: ${ }^{* * *} \mathrm{p}<0.001,{ }^{* *} \mathrm{p}<0.05,{ }^{*} \mathrm{p}<0.1$.

See Table 1 for the meaning of each variable. 
Table 6. Descriptive Statistics by Treatment Status:

Familias en Acción (FA)

\begin{tabular}{lrrrrrr}
\hline \hline & \multicolumn{3}{c}{ Total $(\mathrm{n}=24860)$} & \multicolumn{3}{c}{ Sample $(\mathrm{n}=2345)$} \\
& Treated & Control & Difference & Treated & Control & Difference \\
\hline Pregnancy & & & & & & \\
Age & 0.04 & 0.02 & $0.02^{* * *}$ & 0.04 & 0.04 & 0.00 \\
Standard of living & 16.02 & 15.91 & $0.11^{* * *}$ & 18.95 & 18.84 & 0.11 \\
HH Size & 21.01 & 24.06 & $-3.05^{* * *}$ & 20.69 & 23.93 & $-3.24^{* * *}$ \\
Children & 5.62 & 5.19 & $0.43^{* * *}$ & 5.97 & 5.47 & $0.50^{* * *}$ \\
Rooms & 3.61 & 3.16 & $0.45^{* * *}$ & 4.21 & 3.42 & $0.79^{* * *}$ \\
Students-teacher & 3.87 & 4.24 & $-0.37^{* * *}$ & 4.07 & 4.41 & $-0.34^{* * *}$ \\
Sch-quality & 29.12 & 26.79 & $2.33^{* * *}$ & 30.55 & 28.22 & $2.33^{* * *}$ \\
Private & 304.19 & 335.79 & $-31.60^{* * *}$ & 304.34 & 341.52 & $-37.18^{* * *}$ \\
Distance & 0.10 & 0.31 & $-0.21^{* * *}$ & 0.09 & 0.33 & $-0.24^{* * *}$ \\
Person theft & 2562.71 & 1899.03 & $663.68^{* * *}$ & 2692.03 & 1652.48 & $1039.55^{* * *}$ \\
Motorcycle theft & 0.92 & 1.52 & $-0.60^{* * *}$ & 0.75 & 1.28 & $-0.53^{* * *}$ \\
& 0.10 & 0.15 & $-0.05^{* * *}$ & 0.10 & 0.17 & $-0.07^{* * *}$ \\
\hline \hline
\end{tabular}

Two-tailed significance level: ${ }^{* * *} \mathrm{p}<0.001{ }^{* *} \mathrm{p}<0.05{ }^{*} \mathrm{p}<0.1$.

See Table 1 for the meaning of each variable.

Table 7. Descriptive Diff-in-Diff in Teenage Pregnancy

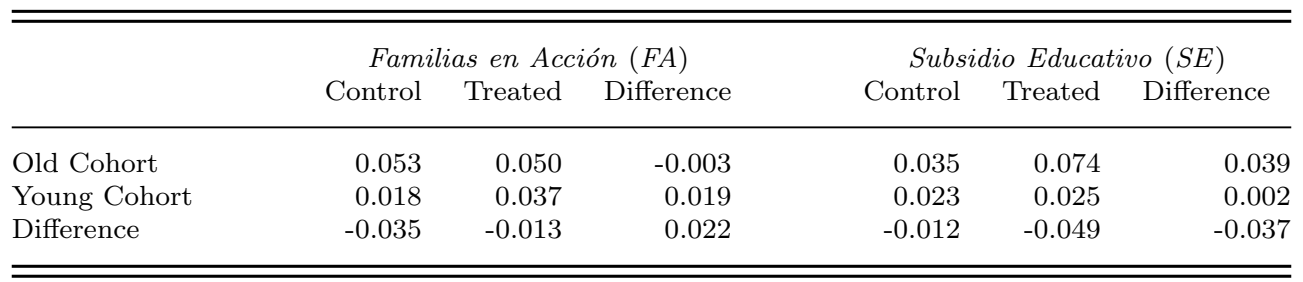

See Table 1 for the meaning of each variable

Table 8. Regressions without controls

\begin{tabular}{lccc}
\hline \hline & $(1)$ & $(2)$ & $(3)$ \\
\hline Cohort x FA & $\begin{array}{c}0.0219^{* *} \\
(0.0103)\end{array}$ & & $\begin{array}{c}0.0176 \\
(0.0165)\end{array}$ \\
Cohort x SE & & $\begin{array}{c}-0.0363^{*} \\
(0.0182)\end{array}$ & $\begin{array}{c}-0.0453^{* *} \\
(0.0208)\end{array}$ \\
School FE & & & $\checkmark$ \\
Observations & 2,345 & 2,345 & 2,345 \\
\hline \hline
\end{tabular}

Standard errors clustered by localidad

$* * * \mathrm{p}<0.001 * * \mathrm{p}<0.05 * \mathrm{p}<0.1$

See Table 1 for the meaning of each variable 
Table 9. General Results

\begin{tabular}{lccccc}
\hline \hline & $(1)$ & $(2)$ & $(3)$ & $(4)$ & $(5)$ \\
\hline Cohort x FA & 0.0176 & 0.0130 & 0.0128 & 0.00892 & 0.0129 \\
& $(0.0165)$ & $(0.0180)$ & $(0.0178)$ & $(0.0188)$ & $(0.0208)$ \\
Cohort x SE & $-0.0453^{* *}$ & $-0.0479^{* *}$ & $-0.0482^{* *}$ & $-0.0454^{* *}$ & $-0.0434^{* *}$ \\
& $(0.0208)$ & $(0.0193)$ & $(0.0193)$ & $(0.0194)$ & $(0.0198)$ \\
School FE & $\checkmark$ & $\checkmark$ & $\checkmark$ & $\checkmark$ & $\checkmark$ \\
Age & & $\checkmark$ & $\checkmark$ & $\checkmark$ & $\checkmark$ \\
Family controls & & & $\checkmark$ & $\checkmark$ & $\checkmark$ \\
School controls & & & & & $\checkmark$ \\
Localidad & & & & & $\checkmark$ \\
Observations & 2,345 & 2,345 & 2,345 & 2,345 & 2,345 \\
\hline \hline
\end{tabular}

Standard errors clustered by localidad

$* * * \mathrm{p}<0.001{ }^{* *} \mathrm{p}<0.05^{*} \mathrm{p}<0.1$

See Table 1 for the meaning of each variable

Table 10. Probit

\begin{tabular}{lcc}
\hline \hline & $(1)$ & $(2)$ \\
\hline Cohort x FA & 0.0187 & 0.0230 \\
& $(0.0234)$ & $(0.0218)$ \\
Cohort x $S E$ & $-0.0238^{* *}$ & $-0.0185^{* * *}$ \\
& $(0.00962)$ & $(0.00705)$ \\
School FE & $\checkmark$ & $\checkmark$ \\
Age & & $\checkmark$ \\
Family controls & & $\checkmark$ \\
School controls & & $\checkmark$ \\
Localidad & 2,345 & 2,289 \\
Observations & \\
\hline \hline
\end{tabular}

Standard errors clustered by localidad

$* * * \mathrm{p}<0.001 * * \mathrm{p}<0.05 * \mathrm{p}<0.1$

See Table 1 for the meaning of each variable 
Table 11. Heterogeneous Effects 1

\begin{tabular}{|c|c|c|c|c|}
\hline & (1) & $(2)$ & $(3)$ & $(4)$ \\
\hline Cohort x $F A$ & $\begin{array}{r}0.0129 \\
(0.0208)\end{array}$ & $\begin{array}{r}0.0135 \\
(0.0208)\end{array}$ & & \\
\hline Cohort x FA 9th grade & & & $\begin{array}{c}0.00916 \\
(0.0337)\end{array}$ & $\begin{array}{c}0.00839 \\
(0.0326)\end{array}$ \\
\hline Cohort $\mathrm{x} F A$ 10th grade & & & $\begin{array}{l}0.0486^{* *} \\
(0.0186)\end{array}$ & $\begin{array}{l}0.0523^{* *} \\
(0.0192)\end{array}$ \\
\hline Cohort x FA 11th grade & & & $\begin{array}{r}-0.00936 \\
(0.0218)\end{array}$ & $\begin{array}{c}-0.00945 \\
(0.0226)\end{array}$ \\
\hline Cohort x $S E$ & $\begin{array}{l}-0.0434^{* *} \\
(0.0198)\end{array}$ & & $\begin{array}{l}-0.0427^{* *} \\
(0.0199)\end{array}$ & \\
\hline Cohort x $S E$ 9th grade & & $\begin{array}{r}-0.0217 \\
(0.0178)\end{array}$ & & $\begin{array}{r}-0.0207 \\
(0.0173)\end{array}$ \\
\hline Cohort x $S E$ 10th grade & & $\begin{array}{l}-0.0586^{* *} \\
(0.0207)\end{array}$ & & $\begin{array}{l}-0.0622^{* * *} \\
(0.0208)\end{array}$ \\
\hline Cohort x $S E$ 11th grade & & $\begin{array}{r}-0.0402 \\
(0.0295)\end{array}$ & & $\begin{array}{r}-0.0362 \\
(0.0299)\end{array}$ \\
\hline Observations & 2,345 & 2,345 & 2,345 & 2,345 \\
\hline
\end{tabular}

Standard errors clustered by localidad

$* * * \mathrm{p}<0.001 * * \mathrm{p}<0.05 * \mathrm{p}<0.1$

Cohort and school fixed effects included in all regressions

See Table 1 for the meaning of each variable 
Table 12. Heterogeneous Effects 2

\begin{tabular}{|c|c|c|c|c|}
\hline & (1) & (2) & (3) & (4) \\
\hline Cohort $\mathrm{x} F A$ & $\begin{array}{r}0.0129 \\
(0.0208)\end{array}$ & $\begin{array}{r}0.0128 \\
(0.0208)\end{array}$ & & \\
\hline Cohort x FA age 14 & & & $\begin{array}{r}-0.00212 \\
(0.0215)\end{array}$ & $\begin{array}{c}-0.00576 \\
(0.0226)\end{array}$ \\
\hline Cohort $\mathrm{x} F A$ age 15 & & & $\begin{array}{r}0.0237 \\
(0.0238)\end{array}$ & $\begin{array}{r}0.0265 \\
(0.0206)\end{array}$ \\
\hline Cohort $\times F A$ age 16 & & & $\begin{array}{c}0.0476^{*} \\
(0.0229)\end{array}$ & $\begin{array}{c}0.0455^{* *} \\
(0.0187)\end{array}$ \\
\hline Cohort x $F A$ age 17 & & & $\begin{array}{c}-0.0143 \\
(0.0365)\end{array}$ & $\begin{array}{c}0.00966 \\
(0.0481)\end{array}$ \\
\hline Cohort $\times F A$ age 18 & & & $\begin{array}{l}-0.0675^{*} \\
(0.0360)\end{array}$ & $\begin{array}{c}-0.102^{*} \\
(0.0513)\end{array}$ \\
\hline Cohort x $S E$ & $\begin{array}{l}-0.0434^{* *} \\
(0.0198)\end{array}$ & & $\begin{array}{l}-0.0436^{* *} \\
(0.0198)\end{array}$ & \\
\hline Cohort x $S E$ age 14 & & $\begin{array}{r}-0.0379 \\
(0.0250)\end{array}$ & & $\begin{array}{r}-0.0308 \\
(0.0227)\end{array}$ \\
\hline Cohort x $S E$ age 15 & & $\begin{array}{l}-0.0460^{* *} \\
(0.0194)\end{array}$ & & $\begin{array}{l}-0.0479^{* *} \\
(0.0172)\end{array}$ \\
\hline Cohort x $S E$ age 16 & & $\begin{array}{r}-0.0266 \\
(0.0280)\end{array}$ & & $\begin{array}{c}-0.0354 \\
(0.0289)\end{array}$ \\
\hline Cohort x $S E$ age 17 & & $\begin{array}{l}-0.0924^{* *} \\
(0.0371)\end{array}$ & & $\begin{array}{c}-0.0895^{*} \\
(0.0453)\end{array}$ \\
\hline Cohort x $S E$ age 18 & & $\begin{array}{r}0.000644 \\
(0.0776)\end{array}$ & & $\begin{array}{r}0.0527 \\
(0.0872)\end{array}$ \\
\hline Observations & 2,345 & 2,345 & 2,345 & 2,345 \\
\hline
\end{tabular}

Standard errors clustered by localidad

$* * * \mathrm{p}<0.001 * * \mathrm{p}<0.05 * \mathrm{p}<0.1$

Cohort and school fixed effects included in all regressions

See Table 1 for the meaning of each variable 
Table 13. Heterogeneous Effects 3

\begin{tabular}{|c|c|c|c|c|}
\hline & (1) & $(2)$ & (3) & (4) \\
\hline Cohort $\mathrm{x} F A$ & $\begin{array}{r}0.0129 \\
(0.0208)\end{array}$ & $\begin{array}{r}0.0128 \\
(0.0209)\end{array}$ & & \\
\hline Cohort $\times F A$ grade 9 age 14 & & & $\begin{array}{r}0.000557 \\
(0.0222)\end{array}$ & $\begin{array}{r}-0.00575 \\
(0.0230)\end{array}$ \\
\hline Cohort $\times F A$ grade 9 age 15 & & & $\begin{array}{r}0.00912 \\
(0.0253)\end{array}$ & $\begin{array}{r}0.0175 \\
(0.0258)\end{array}$ \\
\hline Cohort $\mathrm{x} F A$ grade 9 age 16 & & & $\begin{array}{r}0.0728 \\
(0.179)\end{array}$ & $\begin{array}{r}0.0351 \\
(0.140)\end{array}$ \\
\hline Cohort $\times F A$ grade 9 age 17 & & & $\begin{array}{l}-0.166^{* * *} \\
(0.0237)\end{array}$ & $\begin{array}{l}-0.141^{* * *} \\
(0.0308)\end{array}$ \\
\hline Cohort $\times F A$ grade 9 age 18 & & & $\begin{array}{l}-0.0294 \\
(0.0176)\end{array}$ & $\begin{array}{l}-0.0355^{*} \\
(0.0192)\end{array}$ \\
\hline Cohort $\times$ FA grade 10 age 14 & & & $\begin{array}{r}0.000567 \\
(0.0229)\end{array}$ & $\begin{array}{r}0.00271 \\
(0.0278)\end{array}$ \\
\hline Cohort $\mathrm{x} F A$ grade 10 age 15 & & & $\begin{array}{r}0.0539 \\
(0.0319)\end{array}$ & $\begin{array}{l}0.0510^{*} \\
(0.0279)\end{array}$ \\
\hline Cohort x FA grade 10 age 16 & & & $\begin{array}{l}0.105 * * \\
(0.0485)\end{array}$ & $\begin{array}{l}0.131^{* * * *} \\
(0.0394)\end{array}$ \\
\hline Cohort $\times$ FA grade 10 age 17 & & & $\begin{array}{r}0.0192 \\
(0.0283)\end{array}$ & $\begin{array}{r}0.122 \\
(0.104)\end{array}$ \\
\hline Cohort $\mathrm{x} F A$ grade 10 age 18 & & & $\begin{array}{l}-0.0913^{* * *} \\
(0.0238)\end{array}$ & $\begin{array}{l}-0.0922^{* * *} \\
(0.0221)\end{array}$ \\
\hline Cohort $\times F A$ grade 11 age 15 & & & $\begin{array}{r}-0.0259 \\
(0.0268)\end{array}$ & $\begin{array}{l}-0.0155 \\
(0.0277)\end{array}$ \\
\hline Cohort $\times F A$ grade 11 age 17 & & & $\begin{array}{r}-0.0408 \\
(0.0517)\end{array}$ & $\begin{array}{r}-0.0168 \\
(0.0700)\end{array}$ \\
\hline Cohort $\mathrm{x} F A$ grade 11 age 18 & & & $\begin{array}{l}-0.0641^{*} \\
(0.0334)\end{array}$ & $\begin{array}{l}-0.134^{*} \\
(0.0653)\end{array}$ \\
\hline Cohort x $S E$ & $\begin{array}{l}-0.0434^{* *} \\
(0.0198)\end{array}$ & & $\begin{array}{l}-0.0433^{* *} \\
(0.0198)\end{array}$ & \\
\hline Cohort x $S E$ grade 9 age 14 & & $\begin{array}{r}-0.0289 \\
(0.0239)\end{array}$ & & $\begin{array}{r}-0.0213 \\
(0.0223)\end{array}$ \\
\hline Cohort $\times S E$ grade 9 age 15 & & $\begin{array}{l}-0.0544^{* *} \\
(0.0210)\end{array}$ & & $\begin{array}{l}-0.0548^{* * *} \\
(0.0188)\end{array}$ \\
\hline Cohort x $S E$ grade 9 age 16 & & $\begin{array}{r}0.0427 \\
(0.193)\end{array}$ & & $\begin{array}{r}0.0268 \\
(0.159)\end{array}$ \\
\hline Cohort x $S E$ grade 9 age 17 & & $\begin{array}{l}-0.115^{* *} \\
(0.0429)\end{array}$ & & $\begin{array}{l}-0.0636^{* * *} \\
(0.0219)\end{array}$ \\
\hline Cohort $\mathrm{x} S E$ grade 10 age 14 & & $\begin{array}{l}-0.0578^{*} \\
(0.0302)\end{array}$ & & $\begin{array}{r}-0.0483 \\
(0.0289)\end{array}$ \\
\hline Cohort $\mathrm{x} S E$ grade 10 age 15 & & $\begin{array}{l}-0.0332 \\
(0.0218)\end{array}$ & & $\begin{array}{l}-0.0390^{*} \\
(0.0193)\end{array}$ \\
\hline Cohort x $S E$ grade 10 age 16 & & $\begin{array}{r}-0.0586 \\
(0.0513)\end{array}$ & & $\begin{array}{l}-0.0952^{*} \\
(0.0534)\end{array}$ \\
\hline Cohort x $S E$ grade 10 age 17 & & $\begin{array}{l}-0.111 * * \\
(0.0436)\end{array}$ & & $\begin{array}{r}-0.181 \\
(0.121)\end{array}$ \\
\hline Cohort x $S E$ grade 10 age 18 & & $\begin{array}{l}-0.0533^{* *} \\
(0.0218)\end{array}$ & & $\begin{array}{l}-0.0547^{* *} \\
(0.0209)\end{array}$ \\
\hline Cohort $\mathrm{x} S E$ grade 11 age 15 & & $\begin{array}{l}-0.0637^{* *} \\
(0.0227)\end{array}$ & & $\begin{array}{l}-0.0533^{* *} \\
(0.0212)\end{array}$ \\
\hline Cohort x $S E$ grade 11 age 16 & & $\begin{array}{l}-0.0168 \\
(0.0323)\end{array}$ & & $\begin{array}{r}-0.0195 \\
(0.0314)\end{array}$ \\
\hline Cohort x $S E$ grade 11 age 17 & & $\begin{array}{l}-0.0957^{* *} \\
(0.0395)\end{array}$ & & $\begin{array}{r}-0.0846 \\
(0.0498)\end{array}$ \\
\hline Cohort x $S E$ grade 11 age 18 & & $\begin{array}{r}-0.00719 \\
(0.0947)\end{array}$ & & $\begin{array}{r}0.0970 \\
(0.117)\end{array}$ \\
\hline Observations & 2,345 & 2,345 & 2,345 & 2,345 \\
\hline
\end{tabular}

Standard errors clustered by localidad

$* * * \mathrm{p}<0.001 * * \mathrm{p}<0.05 * \mathrm{p}<0.1$

Cohort and school fixed effects included in all regressions

See Table 1 for the meaning of each variable 
Table 14. Robustness Checks 1

\begin{tabular}{lcrccc}
\hline \hline & $\begin{array}{c}(1) \\
\text { Benchmark }\end{array}$ & $\begin{array}{c}(2) \\
\text { Placebo }^{\dagger}\end{array}$ & $\begin{array}{c}(3) \\
\text { Bootstrap }\end{array}$ & $\begin{array}{c}(4) \\
\text { Drop out }\end{array}$ & $\begin{array}{c}(5) \\
\text { Young Sister }\end{array}$ \\
\hline Cohort x FA & 0.0129 & 0.0134 & 0.0129 & -0.00405 & -0.00348 \\
& $(0.0208)$ & $(0.0479)$ & $(0.0290)$ & $(0.0173)$ & $(0.0229)$ \\
Cohort x SE & $-0.0434^{* *}$ & -0.0393 & $-0.0434^{* *}$ & $-0.0364^{*}$ & $-0.0330^{*}$ \\
& $(0.0198)$ & $(0.0442)$ & $(0.0184)$ & $(0.0205)$ & $(0.0169)$ \\
Observations & 2,345 & 1,251 & 2,345 & 2,838 & 2,193 \\
\hline \hline
\end{tabular}

Standard errors clustered by localidad

$* * * \mathrm{p}<0.001 * * \mathrm{p}<0.05 * \mathrm{p}<0.1$

$\dagger$ Placebo cohort

Cohort and school fixed effects included in all regressions

See Table 1 for the meaning of each variable

Table 15. Robustness Checks 2

\begin{tabular}{lcccc}
\hline \hline & $(1)$ & $(2)$ & $(3)$ & $(4)$ \\
& Benchmark & $\begin{array}{c}\text { Without } \\
19,20,21\end{array}$ & $\begin{array}{c}\text { Without } \\
28-32\end{array}$ & $\begin{array}{c}\text { Without } \\
14,28-32\end{array}$ \\
\hline Cohort x FA & 0.0129 & -0.000670 & -0.00551 & -0.00345 \\
Cohort x SE & $\begin{array}{c}(0.0208) \\
-0.0434^{* *}\end{array}$ & $\begin{array}{c}(0.0563) \\
\left(0.083400^{* *}\right.\end{array}$ & $\begin{array}{l}(0.0618) \\
\left(0.11300^{* * *}\right.\end{array}$ & $\begin{array}{l}(0.0599) \\
\left(0.15500^{* * *}\right.\end{array}$ \\
Observations & 2,345 & $890.0391)$ & $(0.0435)$ \\
\hline \hline
\end{tabular}

Standard errors clustered by localidad

$* * * \mathrm{p}<0.001 * * \mathrm{p}<0.05 * \mathrm{p}<0.1$

Cohort and school fixed effects included in all regressions

See Table 1 for the meaning of each variable

Table 16. Robustness Checks 3

\begin{tabular}{lcccc}
\hline \hline & $\begin{array}{c}(1) \\
\text { Benchmark }\end{array}$ & $\begin{array}{c}(2) \\
\text { P30th }\end{array}$ & $\begin{array}{c}(3) \\
\text { P40th }\end{array}$ & $\begin{array}{c}(4) \\
\text { P50th }\end{array}$ \\
\hline Cohort x FA & $\begin{array}{c}0.0129 \\
(0.0208)\end{array}$ & $\begin{array}{c}0.00607 \\
(0.0409)\end{array}$ & $\begin{array}{c}0.0239 \\
(0.0232)\end{array}$ & $\begin{array}{c}0.0155 \\
(0.0214)\end{array}$ \\
Cohort x SED & $\begin{array}{c}-0.0434^{* *} \\
(0.0198)\end{array}$ & $\begin{array}{c}-0.0379^{*} \\
(0.0186)\end{array}$ & $\begin{array}{c}-0.0409^{* *} \\
(0.0166)\end{array}$ & $\begin{array}{c}-0.0380^{*} \\
(0.0181)\end{array}$ \\
Observations & 2,345 & 2,345 & 2,345 & 2,345 \\
\hline \hline
\end{tabular}

Standard errors clustered by localidad

${ }^{* * *} \mathrm{p}<0.001{ }^{* *} \mathrm{p}<0.05 * \mathrm{p}<0.1$

Cohort and school fixed effects included in all regressions

See Table 1 for the meaning of each variable 
Table 17. Household Effects

\begin{tabular}{|c|c|c|c|}
\hline & (1) & $(2)$ & (3) \\
\hline Cohort x $F A$ & $\begin{array}{r}0.0129 \\
(0.0208)\end{array}$ & $\begin{array}{r}0.0334 \\
(0.0217)\end{array}$ & $\begin{array}{c}0.0518^{*} \\
(0.0273)\end{array}$ \\
\hline Cohort x FA Mother was a Teenage Mother & & $\begin{array}{l}-0.0567^{*} \\
(0.0287)\end{array}$ & \\
\hline Cohort x FA HH Size & & & $\begin{array}{l}-0.00635^{* *} \\
(0.00277)\end{array}$ \\
\hline Cohort x $S E$ & $\begin{array}{l}-0.0434^{* *} \\
(0.0198)\end{array}$ & $\begin{array}{l}-0.0584^{* * *} \\
(0.0184)\end{array}$ & $\begin{array}{l}-0.0632^{* *} \\
(0.0298)\end{array}$ \\
\hline Cohort x $S E$ Mother was a Teenage Mother & & $\begin{array}{r}-0.0106 \\
(0.0231)\end{array}$ & \\
\hline Cohort x $S E$ HH Size & & & $\begin{array}{r}0.00351 \\
(0.00515)\end{array}$ \\
\hline Observations & 2,345 & 1,577 & 2,345 \\
\hline
\end{tabular}

Standard errors clustered by localidad

$* * * \mathrm{p}<0.001{ }^{* *} \mathrm{p}<0.05 * \mathrm{p}<0.1$

Cohort and school fixed effects included in all regressions

See Table 1 for the meaning of each variable 
Table 18. General Results: All Coefficients

\begin{tabular}{|c|c|c|c|c|c|}
\hline & (1) & $(2)$ & (3) & (4) & $(5)$ \\
\hline \multirow[t]{2}{*}{ Cohort } & $-0.0160^{*}$ & $0.0815^{* * *}$ & $0.0839^{* * *}$ & $0.0761^{* * *}$ & $0.0648^{* * *}$ \\
\hline & $(0.00843)$ & $(0.0105)$ & $(0.0104)$ & $(0.0127)$ & $(0.0145)$ \\
\hline \multirow[t]{2}{*}{$F A$} & $-0.125^{* * *}$ & $-0.0976^{* * *}$ & $-0.132^{* * *}$ & $0.0957^{* * *}$ & $0.107^{* * *}$ \\
\hline & $(0.00785)$ & $(0.00930)$ & $(0.0258)$ & $(0.0237)$ & $(0.0287)$ \\
\hline \multirow[t]{2}{*}{$S E$} & $0.406^{* * *}$ & $-0.135^{* * *}$ & $-0.0554 * * *$ & $0.407 * * *$ & -0.0238 \\
\hline & $(0.00991)$ & $(0.0118)$ & $(0.00981)$ & $(0.0129)$ & $(0.0293)$ \\
\hline \multirow[t]{2}{*}{ Cohort x FA } & 0.0176 & 0.0130 & 0.0128 & 0.00892 & 0.0129 \\
\hline & $(0.0165)$ & $(0.0180)$ & $(0.0178)$ & $(0.0188)$ & $(0.0208)$ \\
\hline \multirow[t]{2}{*}{ Cohort x $S E$} & $-0.0453^{* *}$ & $-0.0479^{* *}$ & $-0.0482^{* *}$ & $-0.0454^{* *}$ & $-0.0434^{* *}$ \\
\hline & $(0.0208)$ & $(0.0193)$ & $(0.0193)$ & $(0.0194)$ & $(0.0198)$ \\
\hline \multirow[t]{2}{*}{$S E \times F A$} & $-0.396^{* * *}$ & $0.133^{* * *}$ & $0.102^{* * *}$ & $-0.567 * * *$ & $-0.290 * * *$ \\
\hline & $(0.0125)$ & $(0.0153)$ & $(0.0269)$ & $(0.0213)$ & $(0.0322)$ \\
\hline \multirow{2}{*}{ Cohort x $S E \times F A$} & 0.0238 & 0.0225 & 0.0224 & 0.0284 & 0.0297 \\
\hline & $(0.0259)$ & $(0.0292)$ & $(0.0294)$ & $(0.0297)$ & $(0.0310)$ \\
\hline \multirow[t]{2}{*}{ Age } & & $0.0151^{* * *}$ & $0.0155^{* * *}$ & $0.0153^{* * *}$ & $0.0155^{* * *}$ \\
\hline & & $(0.00169)$ & $(0.00168)$ & $(0.00165)$ & $(0.00166)$ \\
\hline \multirow{2}{*}{ Standard of living } & & & -0.000133 & -0.000135 & -0.000133 \\
\hline & & & $(0.00171)$ & $(0.00171)$ & $(0.00171)$ \\
\hline \multirow[t]{2}{*}{ HH Size } & & & 0.00404 & 0.00398 & 0.00401 \\
\hline & & & $(0.00361)$ & $(0.00359)$ & $(0.00359)$ \\
\hline \multirow[t]{2}{*}{ Children } & & & -0.00506 & -0.00502 & -0.00505 \\
\hline & & & $(0.00307)$ & $(0.00306)$ & $(0.00307)$ \\
\hline \multirow[t]{2}{*}{ Rooms } & & & -0.000222 & -0.000208 & -0.000209 \\
\hline & & & $(0.00347)$ & $(0.00347)$ & $(0.00347)$ \\
\hline \multirow[t]{2}{*}{ Students-teacher } & & & & -0.00154 & $-0.00168^{*}$ \\
\hline & & & & $(0.000917)$ & $(0.000936)$ \\
\hline \multirow[t]{2}{*}{ Sch-quality } & & & & $0.00106^{* * *}$ & $0.00168^{* * *}$ \\
\hline & & & & $(0.000171)$ & $(0.000272)$ \\
\hline \multirow[t]{2}{*}{ Private } & & & & $-0.153^{* * *}$ & $-0.250 * * *$ \\
\hline & & & & $(0.0121)$ & $(0.0197)$ \\
\hline \multirow[t]{2}{*}{ Distance } & & & & $2.66 \mathrm{e}-07$ & $-5.83 \mathrm{e}-05^{* * *}$ \\
\hline & & & & $(4.81 \mathrm{e}-07)$ & $(3.28 \mathrm{e}-06)$ \\
\hline \multirow[t]{2}{*}{ Person theft } & & & & & $0.0142^{* * *}$ \\
\hline & & & & & $(0.00407)$ \\
\hline \multirow[t]{2}{*}{ Motorcycle theft } & & & & & -0.0134 \\
\hline & & & & & $(0.0296) 6$ \\
\hline School FE & $\checkmark$ & $\checkmark$ & $\checkmark$ & $\checkmark$ & $\checkmark$ \\
\hline Age & & $\checkmark$ & $\checkmark$ & $\checkmark$ & $\checkmark$ \\
\hline Family controls & & & $\checkmark$ & $\checkmark$ & $\checkmark$ \\
\hline School controls & & & & $\checkmark$ & $\checkmark$ \\
\hline Localidad & & & & & $\checkmark$ \\
\hline Observations & 2,345 & 2,345 & 2,345 & 2,345 & 2,345 \\
\hline
\end{tabular}

Standard errors clustered by localidad

$* * * \mathrm{p}<0.001{ }^{* *} \mathrm{p}<0.05 * \mathrm{p}<0.1$

See Table 1 for the meaning of each variable 
Table 19. Treatments and covariates

\begin{tabular}{|c|c|c|c|c|c|c|}
\hline & & \multirow{2}{*}{ Total } & \multicolumn{2}{|c|}{ Fam. Acción (FA) } & \multicolumn{2}{|c|}{ Subs. Educ. $(S E)$} \\
\hline & & & Control & Treated & Control & Treated \\
\hline \multirow[t]{3}{*}{ Age } & Old Cohort & 21.823 & 21.856 & 21.745 & 21.909 & 21.709 \\
\hline & Young Cohort & 15.495 & 15.433 & 15.646 & 15.481 & 15.514 \\
\hline & Total & 18.871 & 18.838 & 18.947 & 18.917 & 18.810 \\
\hline \multirow[t]{3}{*}{ Standard of living } & Old Cohort & 22.901 & 23.869 & 20.681 & 23.679 & 21.876 \\
\hline & Young Cohort & 23.028 & 24.001 & 20.695 & 23.823 & 21.992 \\
\hline & Total & 22.960 & 23.931 & 20.688 & 23.746 & 21.930 \\
\hline \multirow[t]{3}{*}{ HH Size } & Old Cohort & 5.658 & 5.520 & 5.974 & 5.546 & 5.806 \\
\hline & Young Cohort & 5.578 & 5.418 & 5.960 & 5.452 & 5.741 \\
\hline & Total & 5.620 & 5.472 & 5.967 & 5.502 & 5.775 \\
\hline \multirow{3}{*}{ Children } & Old Cohort & 3.718 & 3.485 & 4.253 & 3.496 & 4.009 \\
\hline & Young Cohort & 3.593 & 3.354 & 4.168 & 3.401 & 3.844 \\
\hline & Total & 3.660 & 3.423 & 4.214 & 3.452 & 3.932 \\
\hline \multirow[t]{3}{*}{ Rooms } & Old Cohort & 4.313 & 4.414 & 4.082 & 4.487 & 4.085 \\
\hline & Young Cohort & 4.303 & 4.407 & 4.053 & 4.460 & 4.097 \\
\hline & Total & 4.308 & 4.411 & 4.068 & 4.474 & 4.091 \\
\hline \multirow[t]{3}{*}{ Students-teacher } & Old Cohort & 30.554 & 29.827 & 32.219 & 30.909 & 30.086 \\
\hline & Young Cohort & 27.041 & 26.399 & 28.580 & 26.191 & 28.149 \\
\hline & Total & 28.915 & 28.216 & 30.550 & 28.713 & 29.179 \\
\hline \multirow[t]{3}{*}{ Sch-quality } & Old Cohort & 330.184 & 341.650 & 303.903 & 339.987 & 317.276 \\
\hline & Young Cohort & 330.625 & 341.369 & 304.866 & 340.478 & 317.785 \\
\hline & Total & 330.390 & 341.518 & 304.345 & 340.216 & 317.514 \\
\hline \multirow[t]{3}{*}{ Private } & Old Cohort & 0.255 & 0.328 & 0.087 & 0.449 & 0.000 \\
\hline & Young Cohort & 0.261 & 0.330 & 0.093 & 0.460 & 0.000 \\
\hline & Total & 0.258 & 0.329 & 0.090 & 0.454 & 0.000 \\
\hline \multirow[t]{3}{*}{ Distance } & Old Cohort & 1981.257 & 1662.367 & 2712.186 & 2121.354 & 1796.795 \\
\hline & Young Cohort & 1943.588 & 1641.334 & 2668.247 & 2077.276 & 1769.371 \\
\hline & Total & 1963.683 & 1652.484 & 2692.032 & 2100.840 & 1783.961 \\
\hline \multirow[t]{3}{*}{ Person theft } & Old Cohort & 0.821 & 0.930 & 0.570 & 0.904 & 0.710 \\
\hline & Young Cohort & 1.463 & 1.669 & 0.970 & 1.614 & 1.266 \\
\hline & Total & 1.120 & 1.277 & 0.753 & 1.235 & 0.970 \\
\hline \multirow[t]{3}{*}{ Motorcycle theft } & Old Cohort & 0.167 & 0.190 & 0.113 & 0.177 & 0.153 \\
\hline & Young Cohort & 0.136 & 0.156 & 0.087 & 0.143 & 0.126 \\
\hline & Total & 0.152 & 0.174 & 0.101 & 0.161 & 0.140 \\
\hline
\end{tabular}

See Table 1 for the meaning of each variable 
Table 20. Treatments Frequency by Grade

\begin{tabular}{|c|c|c|c|c|c|c|}
\hline & & \multirow{2}{*}{ Total } & \multicolumn{2}{|c|}{ Fam. Acción (FA) } & \multicolumn{2}{|c|}{ Subs. Educ. $(S E)$} \\
\hline & & & Control & Treated & Control & Treated \\
\hline \multirow[t]{3}{*}{ Grade 9} & Old Cohort & $53.32 \%$ & $35.84 \%$ & $17.48 \%$ & $29.87 \%$ & $23.45 \%$ \\
\hline & Young Cohort & $46.68 \%$ & $31.42 \%$ & $15.27 \%$ & $26.33 \%$ & $20.35 \%$ \\
\hline & Total & $100.00 \%$ & $67.26 \%$ & $32.74 \%$ & $56.19 \%$ & $43.81 \%$ \\
\hline \multirow[t]{3}{*}{ Grade 10} & Old Cohort & $53.86 \%$ & $38.80 \%$ & $15.06 \%$ & $29.38 \%$ & $24.48 \%$ \\
\hline & Young Cohort & $46.14 \%$ & $33.90 \%$ & $12.24 \%$ & $25.21 \%$ & $20.93 \%$ \\
\hline & Total & $100.00 \%$ & $72.71 \%$ & $27.29 \%$ & $54.59 \%$ & $45.41 \%$ \\
\hline \multirow[t]{3}{*}{ Grade 11} & Old Cohort & $52.97 \%$ & $36.43 \%$ & $16.54 \%$ & $31.23 \%$ & $21.75 \%$ \\
\hline & Young Cohort & $47.03 \%$ & $32.81 \%$ & $14.22 \%$ & $27.32 \%$ & $19.70 \%$ \\
\hline & Total & $100.00 \%$ & $69.24 \%$ & $30.76 \%$ & $58.55 \%$ & $41.45 \%$ \\
\hline
\end{tabular}

See Table 1 for the meaning of each variable

Table 21. Treatments frequency by Grade

\begin{tabular}{|c|c|c|c|c|c|c|}
\hline & & \multirow{2}{*}{ Total } & \multicolumn{2}{|c|}{ Fam. Acción (FA) } & \multicolumn{2}{|c|}{ Subs. Educ. $(S E)$} \\
\hline & & & Control & Treated & Control & Treated \\
\hline \multirow[t]{3}{*}{ Grade 9} & Old Cohort & 241 & 162 & 79 & 135 & 106 \\
\hline & Young Cohort & 211 & 142 & 69 & 119 & 92 \\
\hline & Total & 452 & 304 & 148 & 254 & 198 \\
\hline \multirow[t]{3}{*}{ Grade 10} & Old Cohort & 440 & 317 & 123 & 240 & 200 \\
\hline & Young Cohort & 377 & 277 & 100 & 206 & 171 \\
\hline & Total & 817 & 594 & 223 & 446 & 371 \\
\hline \multirow[t]{3}{*}{ Grade 11} & Old Cohort & 570 & 392 & 178 & 336 & 234 \\
\hline & Young Cohort & 506 & 353 & 153 & 294 & 212 \\
\hline & Total & 1076 & 745 & 331 & 630 & 446 \\
\hline
\end{tabular}

See Table 1 for the meaning of each variable 
Table 22. Treatments Frequency by Grade and Age Young Cohort

\begin{tabular}{|c|c|c|c|c|c|c|}
\hline & & \multirow[t]{2}{*}{ Total } & \multicolumn{2}{|c|}{ Fam. Acción (FA) } & \multicolumn{2}{|c|}{ Subs. Educ $(S E)$} \\
\hline & & & Control & Treated & Control & Treated \\
\hline \multirow[t]{5}{*}{ Grade 9} & Age 14 & $100.00 \%$ & $68.46 \%$ & $31.54 \%$ & $57.05 \%$ & $42.95 \%$ \\
\hline & Age 15 & $100.00 \%$ & $68.29 \%$ & $31.71 \%$ & $53.66 \%$ & $46.34 \%$ \\
\hline & Age 16 & $100.00 \%$ & $46.15 \%$ & $53.85 \%$ & $53.85 \%$ & $46.15 \%$ \\
\hline & Age 17 & $100.00 \%$ & $83.33 \%$ & $16.67 \%$ & $50.00 \%$ & $50.00 \%$ \\
\hline & Age 18 & $100.00 \%$ & $50.00 \%$ & $50.00 \%$ & $100.00 \%$ & $0.00 \%$ \\
\hline \multirow[t]{5}{*}{ Grade 10} & Age 14 & $100.00 \%$ & $73.17 \%$ & $26.83 \%$ & $63.41 \%$ & $36.59 \%$ \\
\hline & Age 15 & $100.00 \%$ & $78.13 \%$ & $21.88 \%$ & $52.08 \%$ & $47.92 \%$ \\
\hline & Age 16 & $100.00 \%$ & $70.59 \%$ & $29.41 \%$ & $55.88 \%$ & $44.12 \%$ \\
\hline & Age 17 & $100.00 \%$ & $50.00 \%$ & $50.00 \%$ & $46.67 \%$ & $53.33 \%$ \\
\hline & Age 18 & $100.00 \%$ & $80.00 \%$ & $20.00 \%$ & $40.00 \%$ & $60.00 \%$ \\
\hline \multirow[t]{5}{*}{ Grade 11} & Age 14 & $100.00 \%$ & $100.00 \%$ & $0.00 \%$ & $100.00 \%$ & $0.00 \%$ \\
\hline & Age 15 & $100.00 \%$ & $77.27 \%$ & $22.73 \%$ & $55.68 \%$ & $44.32 \%$ \\
\hline & Age 16 & $100.00 \%$ & $72.93 \%$ & $27.07 \%$ & $60.90 \%$ & $39.10 \%$ \\
\hline & Age 17 & $100.00 \%$ & $63.87 \%$ & $36.13 \%$ & $52.94 \%$ & $47.06 \%$ \\
\hline & Age 18 & $100.00 \%$ & $43.75 \%$ & $56.25 \%$ & $59.38 \%$ & $40.63 \%$ \\
\hline
\end{tabular}

See Table 1 for the meaning of each variable

Table 23. Treatments Frequency by Grade and Age Young Cohort

\begin{tabular}{|c|c|c|c|c|c|c|}
\hline & & \multirow{2}{*}{ Total } & \multicolumn{2}{|c|}{ Fam. Acción (FA) } & \multicolumn{2}{|c|}{ Subs. Educ. $(S E)$} \\
\hline & & & Control & Treated & Control & Treated \\
\hline \multirow[t]{5}{*}{ Grade 9} & Age 14 & 149 & 102 & 47 & 85 & 64 \\
\hline & Age 15 & 41 & 28 & 13 & 22 & 19 \\
\hline & Age 16 & 13 & 6 & 7 & 7 & 6 \\
\hline & Age 17 & 6 & 5 & 1 & 3 & 3 \\
\hline & Age 18 & 2 & 1 & 1 & 2 & 0 \\
\hline \multirow[t]{5}{*}{ Grade 10} & Age 14 & 82 & 60 & 22 & 52 & 30 \\
\hline & Age 15 & 192 & 150 & 42 & 100 & 92 \\
\hline & Age 16 & 68 & 48 & 20 & 38 & 30 \\
\hline & Age 17 & 30 & 15 & 15 & 14 & 16 \\
\hline & Age 18 & 5 & 4 & 1 & 2 & 3 \\
\hline \multirow[t]{5}{*}{ Grade 11} & Age 14 & 1 & 1 & 0 & 1 & 0 \\
\hline & Age 15 & 87 & 67 & 20 & 48 & 39 \\
\hline & Age 16 & 266 & 194 & 72 & 162 & 104 \\
\hline & Age 17 & 119 & 76 & 43 & 63 & 56 \\
\hline & Age 18 & 32 & 14 & 18 & 19 & 13 \\
\hline
\end{tabular}

See Table 1 for the meaning of each variable 


\section{References}

[1] Angrist, Joshua and William N. Evans (1996). Schooling and Labor Market Consequences of the 1970 State Abortion Reforms. NBER Working Papers 5406, National Bureau of Economic Research, Inc.

[2] Attanasio, Orazio, Emla Fitzsimos, Ana Gomez, Martha Isabel Gutierrez, Costas Meghir and Alice Mesnard (2010). Children's Schooling and Work in the Presence of a Conditional Cash Transfer Program in Rural Colombia. Economic Development and Cultural Change, Economic Development and Cultural Change, 58 (2), 181-210.

[3] Baird, Sarah, Ephram Chirwa, Craig McIntosh, and Berk Özler (2009). The Short-Term Impacts of a Schooling Conditional Cash Transfer Program on the Sexual Behavior of Young Women. Health Economics, 19 (S1), 55-68.

[4] Barrera, Felipe, Marianne Bertrand, Leigh Linden, and Francisco Perez, (2011). Improving the Design of Conditional Transfer Programs: Evidence from a Randomized Education Experiment in Colombia. American Economic Journal: Applied Economics, $3(2), 167-195$.

[5] Black, Sandra E., Paul J. Devereux and Kjell G. Salvanes (2008). Staying in the classroom and out of the maternity ward? The effect of compulsory schooling laws in teenage births. The Economic Journal, 118 (530), 1025-1054.

[6] de Janvry, Alain, Frederico Finan, Elisabeth Sadoulet and Renos Vakis,(2006). Can conditional cash transfer programs serve as safety nets in keeping children at school and from working when exposed to shocks? Journal of Development Economics, 79 (2), 349 -373 .

[7] Duflo, Esther (2001). Schooling and Labor Market Consequences of School Construction in Indonesia: Evidence from an Unusual Policy Experiment. The American Economic Review, 91 (4), pp 795-813

[8] Duflo, Esther, Pascaline Dupas, Michael Kremer and Samuel Sinei (2006). Education and HIV/AIDS Prevention. Background paper to the 2007 Development Report, The World Bank, Working paper 4024.

[9] Flórez, Carmen E. and Jairo Núñez (2001). Teenage childbearing in Latin American Countries. Interamerican Development Bank, Research Network working paper R-434.

[10] Flórez, Carmen E. and Victoria E. Soto, (2008). El estado de la salud sexual y reproductiva en América Latina y el Caribe: Una visión global. IDB, RES Working Papers, 4572 .

[11] Geronimus, Arline T. and Sanders Korenman, (1992). The socioeconomic consequences of teen childbearing reconsidered. The Quarterly Journal of Economics, 107 (4), 1187121. 
[12] Geronimus, Arline T. (1993). Maternal Youth or Family Background? On the Health Disadvantages of Infants with Teenage Mothers. American Journal of Epidemiology, 137 (2), 213-225.

[13] Hoffman, Saul D., E. Michael Foster, Frank F. Furstenberg, (1993). Reevaluating the costs of teenage childbearing. Demography, 30, 1-13.

[14] Holmlund, Helena (2005). Estimating long term consequences of teenage childbearing: An examination of the sibblings approach. The Journal of Human Resources, 30 (1), 716-743.

[15] Hotz, V. Joseph, Charles H. Mullin and Seth G. Sanders, (1997). Bounding Causal Effects Using Data from a Contaminated Natural Experiment: Analyzing the Effects of Teenage Childbearing. Review of Economic Studies, 64 (4), 576-603.

[16] Hotz, V. Joseph, Susan William McElroy and Seth G. Sanders (2005). Teenage childbearing and its lifecycle consequences: Exploiting a natural experiment. Journal of Human Resources, 40 (3), 683-715.

[17] Levine, David I. and Gary Painter (2003). The Costs of Teenage Out-of-Wedlock Childbearing: Analysis with a Within-School Propensity Score. Review of Economics and Statistics, 85 (4), 884-899.

[18] Lundberg, Shelly and Robert D. Plotnick (1995). Adolescent Premarital Childbearing: Do Economic Incentives Matter? Journal of Labor Economics, 13 (2), 177-200

[19] Miller, Grant (2010). Contraception as Development? New Evidence from Family Planning in Colombia. The Economic Journal, 120 (545), 709-737.

[20] Schultz, T. Paul (2004). School subsidies for the poor: evaluatinf the Mexican progresa poverty program. Journal of Development Economics, 74 (1), 199-250.

[21] Wolfe, B., K. Wilson and R. Haveman (2001). The role of economic incentives in teenage nonmarital childbearing choices. Journal of Public Economics, 81, 473-511. 